\title{
Zika Virus Linked Microcephaly and other Neurological Anomalies Epidemic on Neonatal-Perinatal Medicine: Perspective
}

\section{Ernest Tambo*}

Public Health Pests Laboratories, Jeddah Governate, Jeddah, Saudi Arabia

${ }^{*}$ Corresponding author: Ernest Tambo, Public Health Pests Laboratories, Jeddah Governate, Jeddah, Saudi Arabia, Tel: +237-33-02-51; E-mail: tambo0711@gmail.com

Received date: February 15, 2017; Accepted date: February 17, 2017; Published date: February 20, 2017

Citation: Tambo E (2017) Zika Virus Linked Microcephaly and other Neurological Anomalies Epidemic on Neonatal-Perinatal Medicine: Perspective. Pediatric Infect Dis 1:37. doi: 10.21767/2573-0282.100037

Copyright: (C) 2017, Tambo E. This is an open-access article distributed under the terms of the Creative Commons Attribution License, which permits unrestricted use, distribution, and reproduction in any medium, provided the original author and source are credited.

\section{Editorial}

Zika virus has been isolated from the brains and cerebrospinal fluid of neonates born with congenital microcephaly and other neurological anomalies; and identified in the placental tissue of Zika virus infected women who suffered from consistent clinical symptoms and signs during their pregnancies [1,2]. It started in Brazil in 2015, where Zika virus infection linked unprecedented and unusual cluster cases of microcephaly and other neurological anomalies epidemic during pregnancy was declared as a Public Health Emergency of International Concern by WHO in February 2016 [1,2]. Subsequently, reported in other countries in Caribbean and Atlantic Islands (e.g., Brazil, Colombia, Cuba, Puerto Rica, Martinique, Panama French Polynesia (2013-2014 outbreak of Zika virus), and Africa (Cape Verde) estimated to about 1300 cases led to the robust collective scientific consensus that Zika virus is implicated in congenital abnormalities [2]. Existing evidence and congenital microcephaly, cranio-facial disproportion, spasticity, seizures, irritability and brainstem dysfunction, calcification cortical and ventriculo-megaly neuroimaging, hearing and ocular abnormalities findings, data sharing associated with Zika virus infection in utero acquisition according to WHO [3,4]. Moreover, Zika virus infections that occur later in pregnancy have been associated with poor intrauterine growth, still birth or fetal death and documented acquired in-utero prenatal defects on $X$ rays and ultrasonography imaging reports in some babies have been reported neurological abnormalities and with/without microcephaly with varied degree of severity in Brazil, Cuba, Colombia and Panama to Cape Verde [2,3,5-8].

However, in absence of safe and effective vaccine and therapeutic agents, knowledge gasps and challenges in understanding and defining the local and global short and long lasting public health consequences and cost $[1,3]$. Aedes linked Zika virus emergence, spread of epidemics remain nightmare, worrisome requires promotion neonatal epidemiology, health services research, clinical investigation research and research translation into point of care practices in remotes and resources limited settings on most vulnerable populations in the America, Caribbean, Asian Pacific and Africa [1,2,4].
Ensuring complete coverage of exposure to the full range of Zika and other high risk perinatal and children population illness is fundamental in underlying the neonatal-perinatal and maternal consequences. Further in improving comprehensive, state-of-the-art approach and practice to optimize the diversity of clinical experiences $[5,6]$. Also, in addressing competencies clinical ad medical knowledge gaps, practice-based Zika complication management learning and improvements; while boosting risk communication individual, survivors and other vulnerable communities critical reprisal, appraisal and service delivery. Leveraging on lessons learnt and experiences gotten from recent past Zika virus complications and related health systems surveillance strengths, weaknesses and impact on neonatal-perinatal and maternal interventional research $[2,7,8]$. This is of critical importance in understanding and accelerating newborn epidemiology and clinical research and its applicability to newborns and children based on studies quantitative RT-PCR result in neonates assessment of other potential risk factors Zika virus-specific based IgM/IgG detection during pregnancy confirmed Zika virus infection strength of association in a larger sample size of newborn with microcephaly and other neurological consequences $[3,5,6]$.

Hence, encouraging active of next generation of paediatrics or neonatal scientists and clinical capable of exploring factors that influence and explain new-born and infant health includes antenatal morbidity and mortality. As well as novel surveillance and policy approaches and strategies on neonatal and neonatalperinatal intensive care management, convalescent care, coordination of community consultation delivery on longer-term outcomes of Zika survivors populations and future epidemic events in over 75 vulnerable countries worldwide. This collective commitment and responsibility is core, urgent and imperative; should local and global community to avert or reject to witness another similar future notorious thalidomide birth defects dilemma in the 21st century, which history for every one of all ages will not forgive.

Enhancing effective local private-public stakeholders partnership commitment and investment including international philanthropic organizations and research institutions is crucial in improving Zika congenital anomalies epidemic data and findings 
sharing for evidence policy and resilient prevention care delivery programs $[2,7]$. Furthermore, bridging together interdisciplinary collaboration and innovations is crucial boosting inter-sectorial and multidisciplinary approach including neonatal, paediatric, O\&G, epidemiology, health policy, quality Zika patient-centered communication for quality care delivery improvements and outcomes. Zika population-based operational research on longitudinal cohorts on direct and indirect transmission linked pregnant women and affected families' mental and psychosocial services analysis should be fully resourced to understand and establish improved integrated vector management (IVM), sexual and reproductive interventions and measures. Strengthening Zika routine health system surveillance-response systems and research programs/projects is critical in prevention and control of pregnancy outcomes in prone settings and territories $[6,9,10]$. In addition, elucidating Aedes and sexual transmission related Zika virus transmission ecological, adaptation and human health threat and complications requires coordinated approach to data sharing, surveillance and research is needed in defining the full spectrum of congenital Zika virus syndrome and issues on maternal-child health [11-13]. Innovative approaches in Zika vaccines and therapeutic targets discovery and development should be explored coupled with in silico phylogenetics and phylogeography modelling in understanding its evidence about Zika virus infection congenital abnormalities public health threats $[14,15]$.

The evidence-based causal relationship between Zika virus and microcephaly and other brain anomalies public health and economic impact calls for an urgent need to establish contextual and effective local and global neonatal-perinatal and postnatal longitudinal surveillance-response system policies and interventions implementation [1-3,11-16]. Enhancing robust laboratory data and information and analysis findings to appropriately define Zika viral infection syndrome pre, during and post pregnancy. Important, mapping the expanded spectrum of Zika virus congenital malformations and associated maternal intrauterine effects in guiding need-based clinical and epidemic response interventions and particularly, Zika vaccines for effective and coordinated national and global immunization programs roll out

\section{References}

1. Lyon J (2016) Zika: Worse Than Thalidomide? JAMA 316: 1246-1248.

2. De-Araújo TV, Rodrigues LC, De-Alencar-Ximenes RA, MirandaFilho DDB, Montarroyos UR, et al. (2016) Association between Zika virus infectionand microcephaly in Brazil, January to May, 2016: preliminary report of a case-control study. Lancet Infect Dis 16 : 1356-1363.
3. Costello A, Dua T, Duran P, Gülmezoglu M, Oladapo OT, et al. (2016) Defining the syndrome associated with congenital Zika virus infection. Bull World Health Organ 94: 406-406A.

4. Rasmussen AS, Jamieson JD, Honein AM, Petersen LR (2016) Zika Virus and Birth Defects -Reviewing the Evidence for Causality. N Engl J Med 374: 1981-1984.

5. Panchaud A, Stojanov M, Ammerdorffer A, David Baud MV (2016) Emerging Role of Zika Virus in Adverse Fetal and Neonatal Outcomes. Clin Microbiol Rev 29: 659-694.

6. Der Linden VV, Pessoa A, Dobyns W, Barkovich AJ, Júnior HV, et al. (2016) Description of 13 Infants Born During October 2015January 2016 With Congenital Zika Virus Infection Without Microcephaly at Birth - Brazil. Morb Mortal Wkly Rep 65: 1343-1348.

7. Brito CA, Cordeiro MT (2016) One year after the Zika virus outbreak in Brazil: from hypotheses to evidence. Rev Soc Bras Med Trop 49: 537-543.

8. França GV, Schuler-Faccini L, Oliveira WK, Henriques CM, Carmo $\mathrm{EH}$, et al. (2016) Congenital Zika virus syndrome in Brazil: a case series of the first 1501 livebirths with complete investigation. Lancet 388: 891-897.

9. Klase ZA, Khakhina S, Schneider Ade B, Callahan MV, GlasspoolMalone J, et al. (2016) Zika Fetal Neuropathogenesis: Etiology of a Viral Syndrome. PLoS Negl Trop Dis 10: e0004877.

10. Tambo E, Chuisseu PD, Ngogang JY, Khater El (2016) Deciphering emerging Zika and dengue viral epidemics: Implications for global maternal-child health burden. J Infect Public Health 9: 240-250.

11. Cuevas EL, Tong VT, Rozo N, Valencia D, Pacheco O, et al. (2016) Preliminary Report of Microcephaly Potentially Associated with Zika Virus Infection During Pregnancy-Colombia, JanuaryNovember 2016. Morb Mortal Wkly Rep 165: 1409-1413.

12. Leal MC, Muniz LF, Ferreira TS, Santos CM, Almeida LC, et al. (2016) Hearing Loss in Infants with Microcephaly and Evidence of Congenital Zika Virus Infection-Brazil, November 2015-May 2016. Morb Mortal Wkly Rep 65: 917-919.

13. Danziger P, Berman DR, Luckritz K, Arbour K, Laventhal N (2016) Severe congenital anomalies of the kidney and urinary tract: epidemiology can inform ethical decision-making. J Perinatol 36: 954-959.

14. Zare Mehrjardi M, Poretti A, Huisman TA, Werner H, Keshavarz E, et al. (2017) Neuroimaging findings of congenital Zika virus infection: a pictorial essay. Jpn J Radiol 10.

15. Heukelbach J, Werneck GL (2016) Surveillance of Zika virus infection and microcephaly in Brazil. Lancet 388: 846-847.

16. Tambo E, Madjou G, Khayeka-Wandabwa C, Tekwu EN, Olalubi OA, et al. (2016) Can free open access resources strengthen knowledge-based emerging public health priorities, policies and programs in Africa? F1000Res 5: 853. 